\title{
Removal of Hg from Real Polluted Sediments Using Enhanced-EK Decontamination: Verification of Experimental Methods and Batch-Test Preliminary Results
}

\author{
Danilo Malarbì, ${ }^{1,2}$ Pietro P. Falciglia, ${ }^{2}$ and Federico G. A. Vagliasindi ${ }^{2}$ \\ ${ }^{1}$ Department of Civil Engineering, University of Salerno, Via Ponte Don Melillo, Fisciano, 84084 Salerno, Italy \\ ${ }^{2}$ Department of Civil Engineering and Architecture, University of Catania, Via S. Sofia 64, 95125 Catania, Italy \\ Correspondence should be addressed to Pietro P. Falciglia; ppfalci@dica.unict.it
}

Received 28 November 2014; Accepted 23 March 2015

Academic Editor: José Morillo Aguado

Copyright (C) 2015 Danilo Malarbì et al. This is an open access article distributed under the Creative Commons Attribution License, which permits unrestricted use, distribution, and reproduction in any medium, provided the original work is properly cited.

\begin{abstract}
The aim of the research is to apply a biosurfactant-enhanced-EK technology to marine sediment contaminated by high level of Hg. In this work, data from batch-tests using different novel biosurfactant agents were reported. In addition, a dedicated EK benchscale apparatus was designed and carried out. Technical test was also performed to evaluate the optimal operating features of the EK bench-scale apparatus, assessing the influence of applied voltage and treatment time on the current intensity and electroosmotic flow. Batch experiments were conducted using two sugar esters as biosurfactants and EDTA salt at different concentrations. Results showed that the maximum extraction efficiency was observed for the biosurfactant Olimpicon GC (15\%), for which the Hg extraction was shown to be 3.6-fold higher than for 0.2 M EDTA. From technical tests, the observed reduction of current intensity and electroosmotic flow with time highlights the necessity of using conditioning agents during the treatment. Data demonstrates also the good working features of the experimental apparatus. Preliminary results show that EK treatment jointly with biosurfactants such as sugar esters could be a better choice for the remediation of Hg-polluted sediments. The results obtained are of scientific and practical interest and can be used for further researches.
\end{abstract}

\section{Introduction}

Huge amounts of sediments have dredged every year worldwide for maintenance navigation channels or new harbor constructions: approximately 150 million of cubic meters in Netherlands, Germany, and France and about 300 million in the USA. In Italy, 6 million $\mathrm{m}^{3}$ year ${ }^{-1}$ of sediments were dredged in the past; however this quantity is expected to considerably increase due to the water depth necessary in harbors to face the expanding naval trades. Up to $20 \%$ of these sediments are highly contaminated. At the present, 57 National Priority Sites (NPSs) have been issued in Italy in order to achieve the management of the characterization and remediation procedures under the direct responsibility of the Ministry of the Environment. Twenty-nine of these sites (i.e., $60 \mathrm{~km}^{2}$ in Brindisi, $100 \mathrm{~km}^{2}$ in Priolo, $900 \mathrm{~km}^{2}$ in the Sulcis area, $80 \mathrm{~km}^{2}$ in Taranto, and $75 \mathrm{~km}^{2}$ in the Venice lagoon) require either sediment containment or treatment activities
[1]. High levels of polychlorobiphenyls (PCBs), polycyclic aromatic hydrocarbons (PAHs), high molecular weight $\left(\mathrm{C}_{12}-\right.$ $\mathrm{C}_{40}$ ) petroleum hydrocarbons, and heavy metals, such as mercury, were generally found in contaminated sediments [2]. In particular, extreme $\mathrm{Hg}$ and $\mathrm{PAHs}$ concentrations, exceeding the national and international regulatory guidelines, were recorded as in the case of Augusta Bay (Priolo NPS, Syracuse) [3].

The management of contaminated sediments and their final destination represent key factors for environment and human health. In the case of low contamination levels, repositioning in seawater could be considered; however, disposal to controlled sites could be necessary if the contaminant concentrations are higher than regulatory limits and then not compatible with relocation. In this context, contaminated sediments treatment and their reuse could be valuable and optimal alternatives to disposal. In the case of $\mathrm{Hg}$-contaminated sediments, a "multi-stage" treatment, also called 
"treatment train," may be necessary in order to reduce the contaminant concentrations below the target values. Therefore, the selection of cost-effective treatment technologies represents a relevant challenge for the scientific community. In addition, the characteristics of the sediments, low permeability, high salt, and organic and water contents as well as the presence of further different organic and inorganic contaminants such as PAHs could highly influence the choice of conventional remediation technologies or need innovative solutions. For these reasons, $\mathrm{Hg}$-contaminated sediment remediation is a complex technical issue, which requires the study of different treatment alternatives. Technically and economically feasible treatment strategies need to be identified. The commonly employed and emerging techniques for mercury ex situ remediation are stabilisation/solidification (S/S), thermal desorption, soil washing, or phytoremediation [1]. However, these alternatives could be extremely expensive or long time requiring. Furthermore, sediment physicalchemical and mechanical properties usually result in technical challenges or significant increase of costs.

Among the treatment options, electrokinetic (EK) remediation is documented as a very effective technique, successfully applied to remove heavy metals and a number of organic pollutants from soils, and it could represent an optimal choice for the treatment of heavily contaminated sediments. EK uses a low-level electric voltage across electrodes placed in the polluted matrix in order to lead to the transport of contaminants and water in the porous medium. Under the effect of the electrical voltage, a number of processes take place leading to the transport of contaminants in the porous medium. Furthermore, in order to control system chemistry and promote contaminant solubilization and transport, chemical agents can be added to the process solution. EK has several advantages; among them are the possibility to successfully treat fine and low permeability materials, the limitation of costs achievable with a proper selection of a low current/voltage application, and the possibility to apply a single stage option to reach both dewatering and removal of pollutants, as well as salt for marine sediments [4]. However, EK efficacy has been shown to strongly rely upon sediment and contaminant properties and this issue resulted, in the last few years, in an ever-growing attention by researchers. de Gioannis et al. [5] carried an EK treatment of marine sediment for the removal of heavy metals, including the addition of chelants. They reported that EDTA significantly improved the mobilization (up to 60\%) of the metals (As, Cd, $\mathrm{Cu}, \mathrm{Mn}$, and $\mathrm{Zn}$ ), whereas more aggressive acid conditioning with nitric acid needed to remove $\mathrm{Pb}$ (up to $40.5 \%$ ) from sediment. Comparable results were found by other authors $[6,7]$ also using chelants such as acetic or humic acid. Colacicco et al. [8] investigated the possibility of treating sediments contaminated by heavy metals and PAHs by EK treatment enhanced by EDTA $(0.2 \mathrm{M})$ or surfactant tween 80. Authors reported a metal removal in the range $28-44 \%$. However, removal was found to be significantly improved (up to $84 \%$ ) when both the anodic and cathodic reservoirs were conditioned with the chelating agent EDTA. In terms of PAH removal, a very poor mobilization (up to 7\%) from sediment was observed after a $25 \mathrm{~d}$ treatment.
Very limited studies on $\mathrm{Hg}$ removal from sediments by enhanced-EK have been performed. Pazos et al. [4] carried a work aimed at the treatment of a multipolluted marine sediment $\left(\mathrm{Hg}\right.$ initial contamination level $=1.17 \mathrm{mg} \mathrm{kg}^{-1}$ ). EDTA and surfactant tween 80 were used as processing fluid to enhance the solubility of metals and TPH, respectively. Furthermore, a combination of Fenton's reagent and EDTA was evaluated to promote the degradation of TPH and to solubilize the metals. After a $30 \mathrm{~d}$ treatment, the best results were obtained by EK-Fenton-EDTA process with a removal of about $90 \%$ for $\mathrm{TPH}, 57.3 \%$ for $\mathrm{Zn}, 59.8 \%$ for $\mathrm{Pb}, 59.4 \%$ for $\mathrm{Cu}$, and $54.5 \%$ for $\mathrm{Hg}$. A very low $\mathrm{PAH}$ removal was instead observed. Therefore, an $\mathrm{Hg}$ removal of about $50 \%$ was reachable using a combined EK-Fenton-EDTA process or tween 80 but for treating low $\mathrm{Hg}$ contamination levels. However, the difficulty of treating high $\mathrm{Hg}$ contaminated matrices is well known due to the low solubility of mercury [9]. In addition, mercury has a high affinity for organic matter, and its copresence with other pollutants such as TPHs or PAHs could decrease the effectiveness of EK treatment. This is confirmed by several authors who carried out research on EK remediation of Hg-polluted soils. Subirés-Muñoz et al. [10] studied the effectiveness of some chelant agents (thiosulfate, EDTA, iodide, and $\mathrm{HNO}_{3}$ ) for the remediation of high $\mathrm{Hg}$ pollutions. Authors reported that approximately $30 \%$ of the mercury can be removed at an acceptable rate. Hansen et al. [11], in a study on electrodialytic decontamination of sand polluted with $\mathrm{Hg}$ at $685 \mathrm{mg} \mathrm{kg}^{-1}$, showed an $\mathrm{Hg}$ removal of only $23 \%$. Thöming et al. [12] reported that an electrodialytic remediation method alone was not efficient to remove mercury from a soil containing high proportion of elemental mercury. It was also shown that it is possible to increase the solubility of mercury and then removal rate through adding chemical agents such as KI [13] or iodine/iodide $\left(\mathrm{I}_{2} / \mathrm{I}\right)$ [14-16].

In conclusion, in the case of multipolluted sediments (PAHs and $\mathrm{Hg}$ ) or in the case of high $\mathrm{Hg}$ contamination level, EK could not be totally effective. Furthermore, the high amount of chemicals needed to reach the remediation goal could represent a further cause of pollution. Therefore, the use of more effective, biodegradable, and low-cost enhancing solutions could be very relevant for full-scale applications of EK treatments.

The application of surfactants for enhancing the hydrophobic pollutant removal was object of several studies. Recently, high-degradable surfactants (biosurfactants) have gained much scientific attention due to their environmentalfriendliness $[17,18]$. Biosurfactants enhance the bioavailability and the aqueous solubility of hydrophobic pollutants, due to the ability of increasing the surface area of hydrophobic substrates [19]. Among nonionic biosurfactants, sugar esters could represent a potential optimal choice for environmental treatments. Additionally, these biosurfactants proved to be efficient during flushing of contaminated soil and mobilization of recalcitrant pollutants [20,21].

The aim of the full research activity is to apply a biosurfactant-enhanced-EK technology to marine sediment contaminated by high level of $\mathrm{Hg}$. In this work, preliminary results were reported. The main objectives were (i) to report 
TABLE 1: Physicochemical properties of mercury and its compounds [9].

\begin{tabular}{lccccc}
\hline Properties & $\mathrm{Hg}^{0}$ & $\mathrm{HgCl}_{2}$ & $\mathrm{HgO}$ & $\mathrm{HgS}$ & $\mathrm{CH}_{3} \mathrm{HgOH}$ \\
\hline Melting point $\left({ }^{\circ} \mathrm{C}\right)$ & -38.8 & 277 & $500^{*}$ & $584^{* *}$ & 137 \\
Water solubility $\left(\mathrm{gL}^{-1}\right)$ & $49.610^{-6}$ & 66 & 0.053 & $-10^{-24}$ & - \\
Boiling point $\left({ }^{\circ} \mathrm{C}\right)$ & 356.7 & 303 & - & nd & - \\
Vapor tension $(\mathrm{Pa})$ & 0.18 & 0.009 & $9.210^{-12}$ & 0.9 \\
\hline
\end{tabular}

${ }^{*}$ Decomposition; ${ }^{* *}$ sublimation.

information on $\mathrm{Hg}$ and its compound properties essential for better understanding of $\mathrm{Hg}$ removal mechanisms by using enhanced-EK, (ii) to report data from batch-tests using different novel biosurfactant agents in order to compare their removal efficiency with traditional extracting agent efficiency, and (iii) to design and carry out a dedicated EK bench-scale apparatus and to verify its optimal working features by means of technical tests.

\section{Hg-Polluted Sediments and Their Treatment by Enhanced-EK}

Mercury is regarded as one of the "priority hazardous substances" by the Agency for Toxic Substances and Disease Registry (ATSDR) because of its toxicity, mobility, and long residence time in environment [9]. The physicochemical properties of mercury and its main compounds are given in Table 1. Anthropogenic activities which include coal combustion, waste incineration, metal refining and manufacturing, and chloralkali production discharged a large amount of mercury into the environment. The recent estimation of global mercury emissions ranges from 5000 to 8000 metric tons per year [22]. Available data clearly shows that contamination of sediments will result in an elevated accumulation of mercury to fish and, by means of food chain processes, will consequently pose a direct threat to the human health [10].

In presence of water, deposited $\mathrm{Hg}$ can be transformed by soil bacteria to a more toxic form of mercury, namely, methylmercury ( $\mathrm{MeHg}$ ). In addition, mercury can be trapped by organic matter, and this plays a major role in its distribution and transport. For this reason, the copresence of other pollutants such as TPHs or PAHs could drastically decrease the treatment efficiency in terms of Hg removal. Under oxidizing conditions, elemental mercury $\left(\mathrm{Hg}^{0}\right)$ can be oxidized to the $\mathrm{Hg}^{\mathrm{II}}$ valance state, which is a much more reactive form able to undergo methylation and/or reactions with inorganic species. Under reducing conditions, $\mathrm{Hg}^{\mathrm{II}}$ may be converted back to its elemental $\left(\mathrm{Hg}^{0}\right)$ state. In general, the transport and fate of $\mathrm{Hg}^{\mathrm{II}}$ depend on several environmental factors, particularly the sediment-solution chemistry and the $\mathrm{pH}$, redox potential (Eh), and the strains of bacteria that are present [9].

EK uses a low-level voltage $(\Delta \mathrm{V})$ in the order to generate an electric field $\left(\Delta \mathrm{V} \mathrm{cm}^{-1}\right)$ and an electrical current by means of electrodes placed across the contaminated region. Under this effect, a number of processes take place leading to the transport of contaminants in the porous medium. Furthermore, the following reactions occur at the electrodes [23]:

(i) $2 \mathrm{H}_{2} \mathrm{O}-4 \mathrm{e}^{-} \rightarrow \mathrm{O}_{2} \uparrow+4 \mathrm{H}^{+}$(anode)

(ii) $2 \mathrm{H}_{2} \mathrm{O}+2 \mathrm{e}^{-} \rightarrow \mathrm{H}_{2} \uparrow+2 \mathrm{OH}^{-}$(cathode).

Thus, as the electrokinetic treatment proceeds, gas evolution occurs at the electrodes, whereas $\mathrm{pH}$ drops at the anode and rises at the cathode as a result of generation of $\mathrm{H}^{+}$and $\mathrm{OH}^{-}$ions, respectively. Because the effective ionic mobility of the hydrogen ion is about 1.8 times that of the hydroxyl ion, an acidic front migrating towards the cathode is generated, which is responsible for the mobilization of contaminants from the solid material. During EK treatment, the transport of species consists of mass fluxes generated by diffusion, electromigration, electroosmotic advection (also called electroosmosis), and electrophoresis. Among them, electromigration and electroosmosis generally play the most relevant role in determining transport phenomena towards the electrodes. During the electrokinetic process, sorption/desorption and precipitation/dissolution reactions affect the extent of contaminant transport across the porous media and the performance of the decontamination process. As mentioned before, such processes are also influenced by the migration of the acidic front. Thus, it is clear that the efficacy of an electrokinetic remediation process strongly relies upon sediment properties (including mineralogy, organic matter content) and chemical behavior of the contaminants. As far as trace metals are concerned, surface complexation, sorption, and ion exchange mechanisms strongly counteract mobilization from the negatively charged clay particles. In order to control system chemistry and promote contaminant solubilization and transport, chemical agents can be added to the process solution. If additional solutions are employed in order to increase the mobility of the contaminant, the treatment is called enhanced-EK. The identification of the most proper enhancing chemicals is an issue of critical relevance for the on-going research in contaminated sediment treatment.

In the case of $\mathrm{Hg}$ contamination, since mercury species can be bound in micropores, diffusion phenomena limit the contaminant extraction processes. Electromigration and electroosmosis are the main transport mechanisms responsible for electrokinetic $\mathrm{Hg}$ movement in sediments [12]:

(i) electromigration: if dissolved $\mathrm{Hg}$ is present at high $\mathrm{pH}$ or high halide concentration as an anion complex and it moves towards the anode (for high concentrations of mercury in the liquid phase, the process becomes $\mathrm{pH}$ sensitive), 


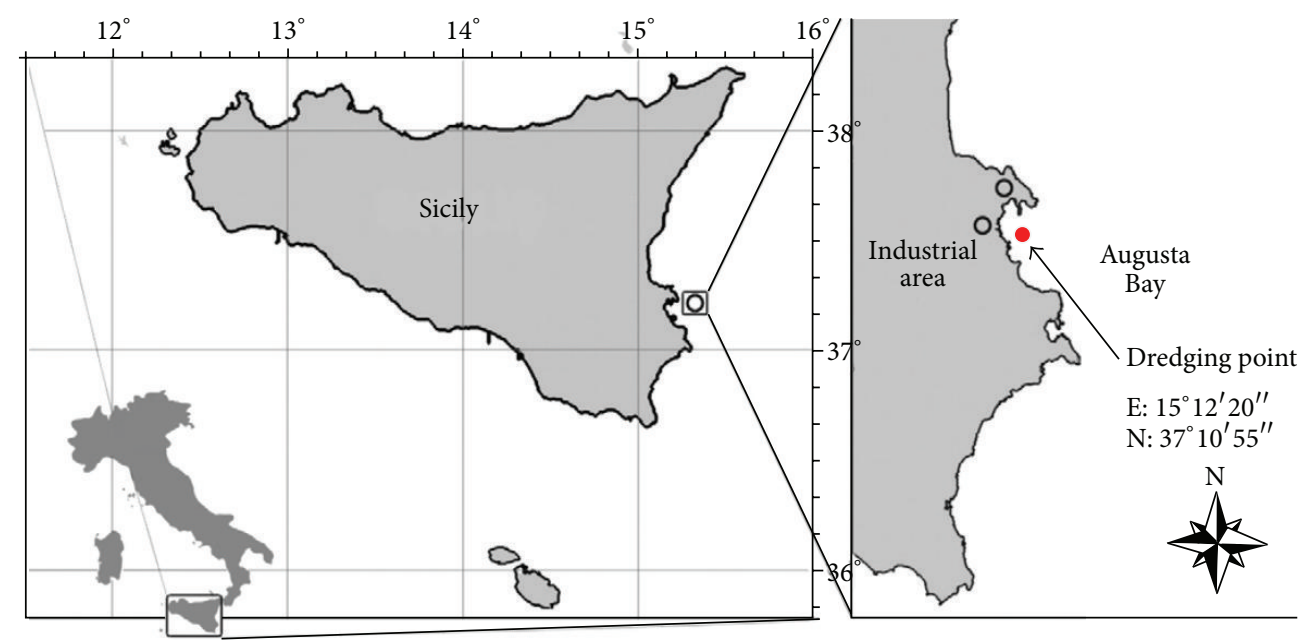

Figure 1: Location of sediment sampling point (Augusta Bay, Syracuse, Italy).

(ii) electroosmosis: when the flow of the pore water can result in a transport of charged as well as uncharged species present in the pore liquid towards the cathode.

In particular, in soils or sediments, the main part of the mercury species occurs in or attached to a solid phase. $\mathrm{Hg}^{0}$ as well as $\mathrm{Hg}^{\mathrm{I}}$ - and $\mathrm{Hg}^{\mathrm{II}}$-precipitates may form a liquid phase and a solid phase, respectively. Other mercury species, mainly $\mathrm{Hg}^{\mathrm{II}}$-species such as $\mathrm{HgS}, \mathrm{HgCl}_{2}, \mathrm{Hg}(\mathrm{OH})_{2}$, or toxic organic forms like dimethylmercury, $\left(\mathrm{CH}_{3}\right)_{2} \mathrm{Hg}$, are physicochemically bound by different sediment phases. The strength of this binding varies to a large extent. For example, $\mathrm{Hg}^{2+}$ that is adsorbed on iron oxide surfaces is tightly bound but may be mobilized, whereas $\mathrm{Hg}^{2+}$ that is bound chemically by sulphur can hardly be removed without attacking the whole molecule. Some of these species are available for electrokinetic transport, while others are not. The solubility of $\mathrm{Hg}$ compounds is in a very wide range. $\mathrm{HgS}$ has a very low aqueous solubility, and this limits its removal by electroosmosis, whereas $\mathrm{Hg}^{\mathrm{II}}$ with inorganic ligands $\left(\mathrm{Cl}^{-}\right.$and $\left.\mathrm{OH}^{-}\right)$forms complexes with higher solubility. The aqueous solubility of $\mathrm{HgCl}_{2}, \mathrm{Hg}_{2} \mathrm{Cl}_{2}$, and $\mathrm{HgO}$ are 70,000, 2.0, and $53 \mathrm{mg} \mathrm{L}^{-1}$, respectively, whereas the solubility of $\mathrm{HgS}$ is only $10 \mu \mathrm{g} \mathrm{L}^{-1}$ [13]. Therefore, the presence of low amount of sulfide represents an advantage due to the greater tendency for $\mathrm{Hg}$ to associate with $\mathrm{Cl}^{-}$and/or $\mathrm{OH}^{-}$. Therefore, Hg species that are weakly bound by the solid bulk phase can be transported by means of electroosmotic mechanisms or electromigration, but both mechanisms need the $\mathrm{Hg}$ molecules being available within the liquid phase (dissolved), thus with high solubility. This amount of dissolved species is controlled by equilibrium reactions, and there are three fundamental parameters characterizing the solution, the $\mathrm{pH}$, the redox potential, and the concentration of dissolved ions. These parameters could be modified by adding appropriate chemicals like acids, oxidizing or complexing agents. Reddy and Saichek [13] reported that $\mathrm{HgS}, \mathrm{Hg}(\mathrm{l})$, $\mathrm{HgO}, \mathrm{Hg}_{2} \mathrm{Cl}_{2}$, and $\mathrm{HgCl}_{2}$ are thermodynamically stable solidphase species, and to allow the formation of the $\left(\mathrm{HgI}_{4}\right)^{2-}$ soluble complex requires oxidation by potassium iodide $(\mathrm{KI})$, iodine $\left(\mathrm{I}_{2}\right)$, iodide $\left(\mathrm{I}^{-}\right), \mathrm{I}_{2} / \mathrm{I}^{-}$lixiviant solution at the cathode, or another oxidizing agent. In this case, removal is based on the electromigration of the $\left(\mathrm{HgI}_{4}\right)^{2-}$ complexes towards the anode. However, strong oxidizing conditions are not essential if the initial state of the $\mathrm{Hg}$ contaminant is $\mathrm{HgCl}_{2}$ which is not a relatively insoluble species like $\operatorname{HgS}[9,16]$.

\section{Materials and Methods}

3.1. Sediment Sampling and Characterization. For the experiments, $20 \mathrm{~kg}$ of sediments was dredged from Augusta Bay (Priolo NPS, Syracuse, Italy) and collected at a water depth of $20 \mathrm{~m}$ (E: $15^{\circ} 12^{\prime} 20^{\prime \prime}$; N: $37^{\circ} 10^{\prime} 55^{\prime \prime}$ ) (Figure 1). After dredging, the material was homogenized and stored under controlled conditions and then air-dried for $72 \mathrm{~h}$, before their characterization. Five samples were analyzed for different physicochemical properties as well as contaminant content according to the respective standard testing procedures. The average values were reported. Specifically, metal content was determined using US-EPA 3051A and 6020A methods, whereas PAH content was determined using US-EPA 3580A, 3640A, and 8270D methods.

3.2. Batch-Tests. In order to demonstrate the potential applicability of two novel biosurfactants, two sugar esters and EDTA salt at different concentrations were selected for batch experiments. Both selected biosurfactants were nonionic, namely, Glyceryl Cocoate 70E (Olimpicon GC) and Alkyl Glucoside (Olimpicon SG/W), and were purchased from Industria Chimica Olimpia Tensioattivi s.r.l. (Cavenago di Brianza, Monza-Brianza, Italy) as commercially available products. EDTA salt was obtained from Merck KGaA (Darmstadt, Germany). Batch-test experimental matrix is reported in Table 2.

Batch-tests were conducted in $60 \mathrm{~mL}$ glass vials at a sediment to solution ratio of $1: 4$. Thirty-two $\mathrm{mL}$ of each solution was added to $8 \mathrm{~g}$ of sediment sample; then the vials were 
TABLE 2: Experimental matrix for batch tests.

\begin{tabular}{llllc}
\hline Treatment & Enhancing agent & Type & Composition & $\begin{array}{c}\text { Solution } \\
\text { concentration }\end{array}$ \\
\hline B1-05 & Olimpicon GC & Nonionic biosurfactant (sugar ester) & Glyceryl Cocoate 70E & $5 \%$ \\
B2-15 & & & Alkyl Glucoside & $15 \%$ \\
\hline B2-05 & Olimpicon SG/W & Nonionic biosurfactant (sugar ester) & $5 \%$ & $15 \%$ \\
B2-15 & & & Ethylenediaminetetraacetic acid & $0.1 \mathrm{M}$ \\
B3-01 & EDTA & Chelant agent & $\left(\mathrm{C}_{10} \mathrm{H}_{14} \mathrm{~N}_{2} \mathrm{Na}_{2} \mathrm{O}_{8} \cdot 2 \mathrm{H}_{2} \mathrm{O}\right)$ & $0.2 \mathrm{M}$ \\
B3-02 & & &
\end{tabular}

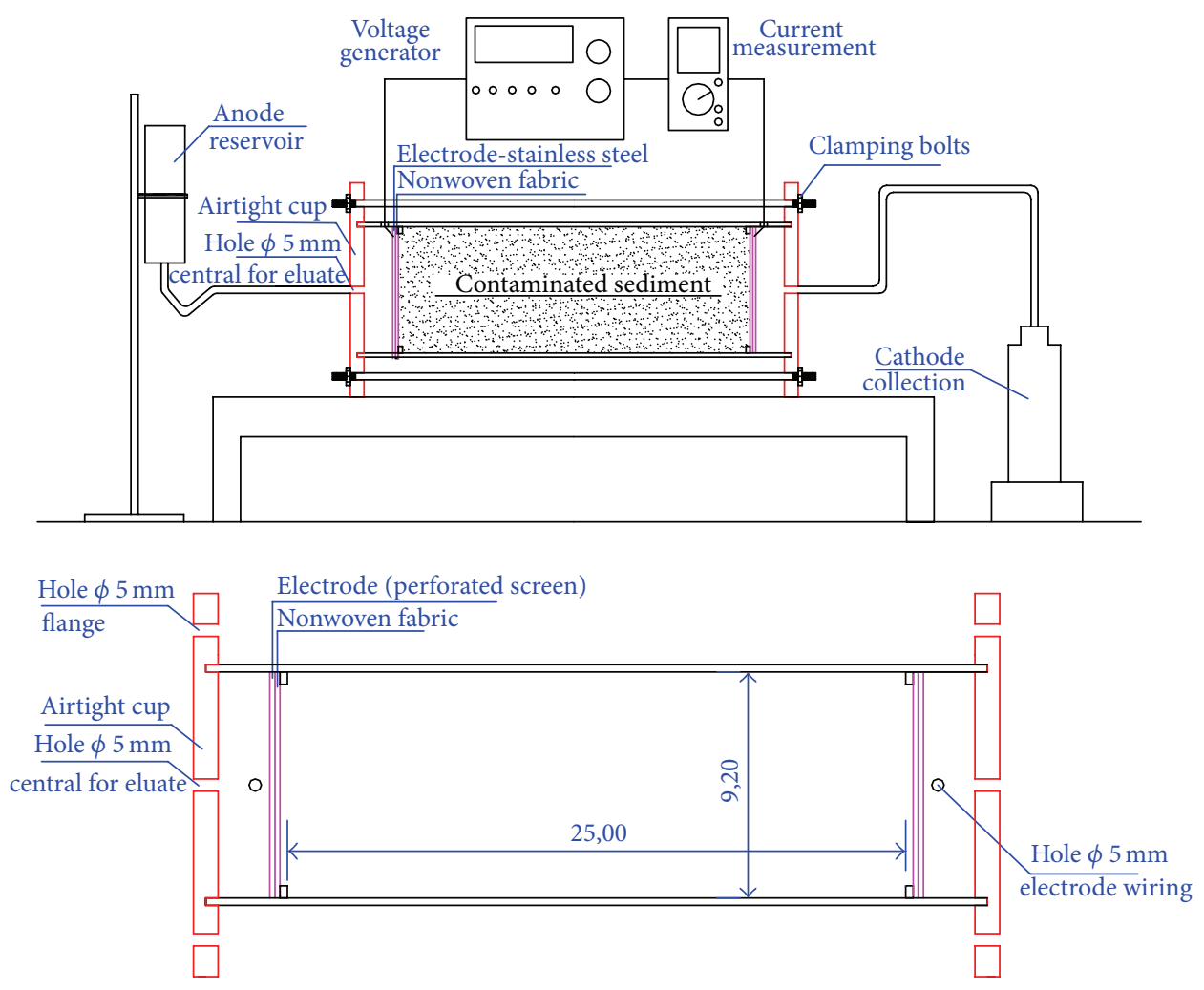

FIGURE 2: Schematic of the experimental apparatus.

shaken using a shaker table at $160 \mathrm{rpm}$ for $24 \mathrm{~h}$. After the procedure was completed, the mixture was centrifuged at $500 \mathrm{rpm}$ for $10 \mathrm{~min}$. At the end of the test, all the vials were taken out from the shaker for $\mathrm{pH}$ and $\mathrm{Hg}$ concentration measurements in the supernatant liquid. $\mathrm{Hg}$ in the solution was determined by liquid-liquid extraction followed by ICPMS analysis (US-EPA 200.8 method). All tests were carried out in replicate and average values were shown.

3.3. EK Test: Experimental Apparatus and Procedures. In order to investigate the removal of $\mathrm{Hg}$ from heavy polluted sediments by using EK technology, a bench-scale apparatus was designed and carried out. The apparatus consisted of a Plexiglas cylindrical migration chamber $(250 \mathrm{~mm}$ in length and $92 \mathrm{~mm}$ in internal diameter) and two electrode chambers where electrodes were placed (Figures 2 and 3). Electrodes were electrically connected to a DC power supply providing a constant electric potential $(\Delta \mathrm{V})$ across the two electrodes. A multimeter was also used for current intensity variation measurement during the treatment.

In this work, preliminary tests, demonstrating the functionality of the apparatus and the experimental methods, were reported. Specifically, the influence of using a solution of biosurfactant as anodic extracting on the variation of current intensity $(i)$ and electroosmotic flow $(Q)$ and the opportunity of employing EDTA as conditioning agent at the cathode were assessed. For experiments, $2.0 \mathrm{~kg}$ sediment sample was used to fill the migration chamber. A constant $\Delta \mathrm{V}$ of $30 \mathrm{~V}$ (potential gradient of $1.2 \mathrm{~V} \mathrm{~cm}^{-1}$ ) was applied through the sediment for selected periods. Deionized water or biosurfactant solution (15\%, Olimpicon GC-Olimpicon $\mathrm{SG} / \mathrm{W}, 1: 1)$ was used as processing fluid in tests EK1 and 

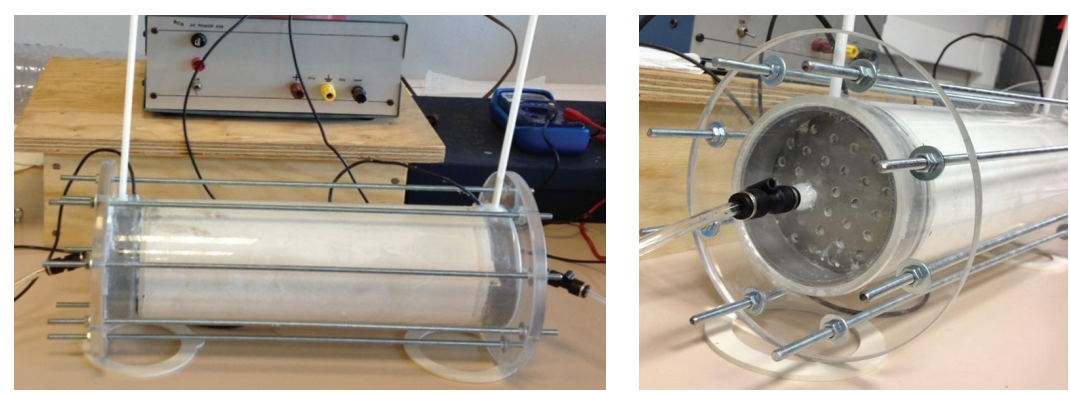

FIgURE 3: Experimental apparatus.

TABle 3: Experimental matrix for EK tests.

\begin{tabular}{lcccc}
\hline Test & Time $(\mathrm{h})$ & $\Delta \mathrm{V}(\mathrm{V})$ & $\begin{array}{c}\text { Processing fluid } \\
\text { (anodic chamber) }\end{array}$ & $\begin{array}{c}\text { Conditioning agent } \\
\text { (cathodic chamber) }\end{array}$ \\
\hline EK1 & 30 & 30 & Deionized water & - \\
\hline EK2 & 180 & 30 & $0-140$ biosurfactant solution & $0-99 \mathrm{~h} \mathrm{(none)}$ \\
\hline
\end{tabular}

EK2, respectively. For EK2 test, the cathode was conditioned with an EDTA solution $(0.1 \mathrm{M})$ after $100 \mathrm{~h}$, whereas the anode was conditioned with an EDTA solution (0.1 M) with the biosurfactant solution $(1: 1)$ after $140 \mathrm{~h}$. The assessment of the conditioning effects is essential in order to avoid precipitation effect at cathode. Total treatment times were 30 and $180 \mathrm{~h}$, for EK1 and EK2, respectively. The current intensity ( $i)$ and the electroosmotic flow $(Q)$ were measured during the test. The experimental matrix is reported in Table 3.

\section{Results and Discussion}

4.1. Sediments Characterization. Results from sediment characterization are reported in Table 4 . From grain size analysis, the sediments were classified as silt, with the $0-50 \mu \mathrm{m}$ fraction accounting for over than $90 \%$ of the material. In addition, typical high moisture for sediments of $40.17 \%$ was found. In terms of contaminants, a high $\mathrm{Hg}$ concentration of $28.20 \mathrm{mg} \mathrm{kg}^{-1}$ was detected, while PAHs concentrations less than $0.010 \mathrm{mg} \mathrm{kg}^{-1}$ were found for all the samples. The Italian L.D. 152/2006 reports an $\mathrm{Hg}$ limit for contaminated sediments of $1 \mathrm{mg} \mathrm{kg}^{-1}$. The sediment characterization confirmed EK treatment as an optimal potential choice for its treatment, especially due to the fine grain texture and the high moisture. The challenge is mainly $\mathrm{Hg}$ removal. The present work focused on this specific issue.

4.2. Batch-Tests. The effects of type and dosage of biosurfactant or EDTA solution on the solution $\mathrm{pH}$ and the Hg extraction from sediments were evaluated. As shown in Table 5, the nature of the product employed influenced the $\mathrm{pH}$ of the extracting solution, whereas, for all the treatments, any significant $\mathrm{pH}$ variation due to its dosage was not observed. In addition, type and concentration of the solution seem to play a major rule in terms of $\mathrm{Hg}$ extraction; however, no correlation between $\mathrm{pH}$ value and extracted $\mathrm{Hg}$ was observed. For all the investigated treatments, the extraction
TABle 4: Physicochemical properties of dredged sediments.

\begin{tabular}{|c|c|}
\hline \multicolumn{2}{|c|}{ Particle size distribution } \\
\hline Diameter $(\mathrm{mm})$ & Distribution (\%) \\
\hline $0-0.062$ (clay) & 3.5 \\
\hline $0.062-0.5$ (silt) & 87.9 \\
\hline $0.5-2.0$ (sand) & 8.3 \\
\hline$>2.0$ (gravel) & 0.3 \\
\hline $\mathrm{pH}$ & 8.0 \\
\hline Moisture (\%) & 40.17 \\
\hline Metals & $C\left(\mathrm{mg} \cdot \mathrm{kg}^{-1}\right)$ \\
\hline As & 8.33 \\
\hline $\mathrm{Cd}$ & 0.46 \\
\hline Cr tot & 47.93 \\
\hline $\mathrm{Hg}$ & 28.20 \\
\hline $\mathrm{Ni}$ & 29.90 \\
\hline $\mathrm{Pb}$ & 29.77 \\
\hline $\mathrm{Cu}$ & 51.40 \\
\hline $\mathrm{Zn}$ & 91.17 \\
\hline \multicolumn{2}{|c|}{ PAHs } \\
\hline Single PAH & $C\left(\mathrm{mg} \cdot \mathrm{kg}^{-1}\right)$ \\
\hline Naphthalene & $<0.010$ \\
\hline Acenaphthylene & $<0.010$ \\
\hline Acenaphthene & $<0.010$ \\
\hline Phenanthrene & $<0.010$ \\
\hline Anthracene & $<0.010$ \\
\hline Fluoranthene & $<0.010$ \\
\hline Pyrene & $<0.010$ \\
\hline Benzo(a)anthracene & $<0.010$ \\
\hline Chrysene & $<0.010$ \\
\hline Benzo(b)fluoranthene & $<0.010$ \\
\hline Benzo(k)fluoranthene & $<0.010$ \\
\hline Benzo(a)pyrene & $<0.010$ \\
\hline Perylene & $<0.010$ \\
\hline Benzo(g,h,i)perylene & $<0.010$ \\
\hline Dibenz(a,h)anthracene & $<0.010$ \\
\hline
\end{tabular}

efficiency increased with increasing concentration of the agents. The maximum $\mathrm{Hg}$ extraction efficiency was $0.18 \%$ 
TABLE 5: $\mathrm{pH}$ and $\mathrm{Hg}$ extraction for all the treatments.

\begin{tabular}{lccccc}
\hline Treatment & \multirow{2}{*}{ Enhancing agent } & Solution concentration & $\mathrm{pH}$ & $\begin{array}{c}\text { Hg recovered } \\
\left(\mu \mathrm{gL}^{-1}\right)\end{array}$ & Hg extraction $(\%)$ \\
\hline B1-05 & \multirow{2}{*}{ Olimpicon GC } & $5 \%$ & 6.51 & 1.18 & 0.02 \\
B1-15 & & $15 \%$ & 6.68 & 12.88 & 0.18 \\
\hline B2-05 & \multirow{2}{*}{ Olimpicon SG/W } & $5 \%$ & 10.22 & 5.33 & 11.15 \\
B2-15 & & $15 \%$ & 10.36 & 0.55 & 0.16 \\
\hline B3-05 & \multirow{2}{*}{ EDTA } & $0.1 \mathrm{M}$ & 5.20 & 3.68 & 0.01 \\
B3-15 & & $0.2 \mathrm{M}$ & 4.98 & 0.05 \\
\hline
\end{tabular}

for the treatment B1-15 (Olimpicon GC, 15\%). In this case, $\mathrm{Hg}$ extraction was shown to be 3.6-fold higher than for the B3-02 (0.2 M EDTA) solution and slightly higher than $\mathrm{B} 2-15$. This highlights higher $\mathrm{Hg}$ removal for biosurfactant solutions especially if compared with conventional EDTA extracting agent. The nondependence of the $\mathrm{Hg}$ extraction on the $\mathrm{pH}$ value of the solution remarks that the key factor of removal process is represented by the ability of selected products of enhancing bioavailability and aqueous solubility of pollutants. Conventional and biosurfactants can organize their structure in molecular aggregates called "micelles" and able to contain hydrophobic substances due to their ionised "heads." This results in the entrapment of low-soluble contaminants allowing their solubilization in water and thus removal. Specifically, critical micelle concentration (CMC) is defined as the concentration of surfactants above which the system allows the micelle formation. Before CMC reaching, the surface tension strongly changes with the concentration of the surfactant, whereas, after its reaching, the surface tension does not significantly change. At this point, any further surfactant addition will not result in an increase of the number of micelles and then in an increase of the emulsifying effect. Results from batch-tests suggest that an EK treatment using Olimpicon has a great potentiality for remedying sediments with high $\mathrm{Hg}$ levels. Previous studies reported that the amount of biosurfactant is fundament for technical and environmental features due to its high biodegradability. However, biosurfactants may inhibit the removal processes. It was shown [24] that the formation of emulsions during the removal process increases the viscosity, and its small increase has a noticeable effect on the mobilization process, due to pore clogging and reduction of flow, which inhibits the $\mathrm{Hg}$ removal. For this reason, EK tests were also performed in order to compare biosurfactant processing solution and deionized water in terms of influence on the electroosmotic flow variation.

4.3. EK Test. Current intensity (i) through the sediment and electroosmotic flow $(Q)$ as a function of treatment time were assessed. Results (Figures 4-6) showed that, for EK1, $i$ slightly decreased within the first $20 \mathrm{~h}$ from 3.70 to $3.30 \mathrm{~mA}$, while a further heavy reduction (about $1 \mathrm{~mA}$ ) was observed for a treatment time in the range $20-30 \mathrm{~h}$. At the same time, a reduction of $Q$ that followed the same trend was observed. Consequently, the variation of the cumulative $Q$ tended to an asymptotic value. This behavior is due to the hydroxide

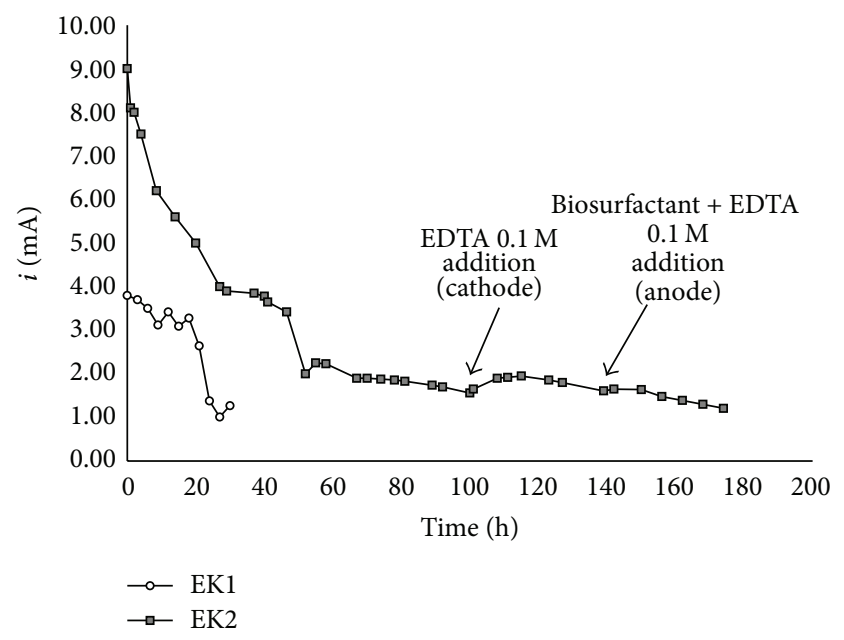

FIGURE 4: Electric current intensity $(i)$ as a function of treatment time (EK1, EK2).

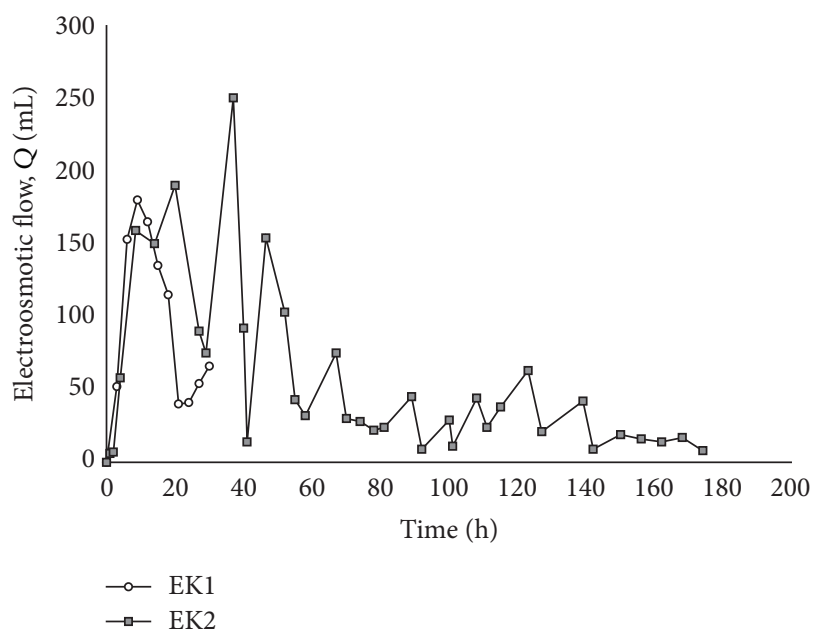

Figure 5: Electroosmotic flow $(Q)$ as a function of treatment time (EK1, EK2).

precipitation near the cathode section able to reduce electric and hydraulic conductibility of the medium. The necessity of using conditioning agents or a processing fluid different than deionized water in order to avoid this phenomenon is clear. A similar qualitative trend was observed for the EK2 treatment 


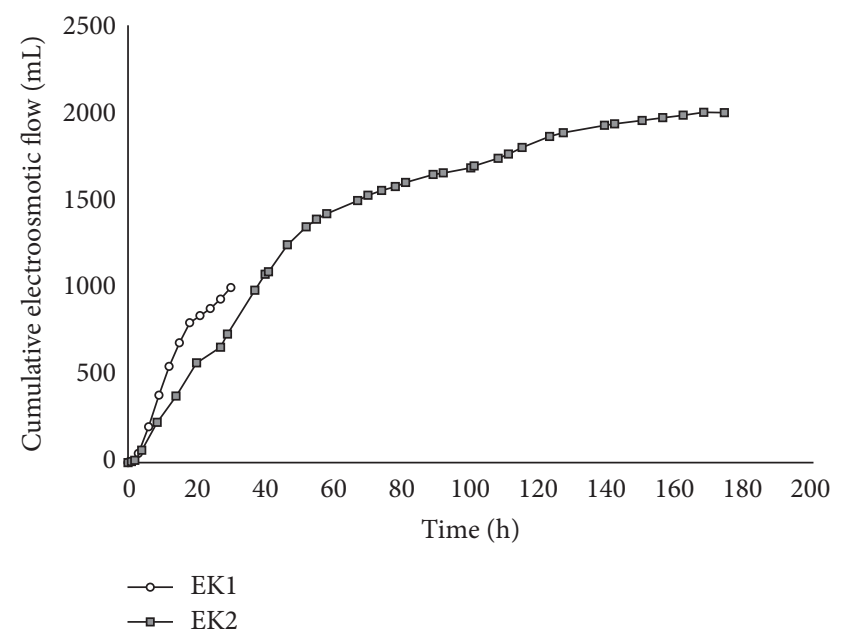

FIgURE 6: Cumulative electroosmotic flow $(Q)$ as a function of treatment time (EK1, EK2).

where biosurfactant was employed as processing fluid, but higher values than EK1 (about 2-fold) were recorded. A slight increase of $i$ and $Q$ was also observed when the EDTA solution was added at the cathode, demonstrating the ability of EDTA to accelerate the electroosmotic phenomena. A similar behavior was also recorded when biosurfactant solution was replaced after $140 \mathrm{~h}$ with EDTA-biosurfactant solution. Obtained data are in agreement with results found in another similar research [5] and demonstrate the good working features of the experimental apparatus.

\section{Conclusions}

The following conclusions have been drawn according to the experimental results presented above.

(i) The nature and the amount of the products employed significantly influenced the $\mathrm{Hg}$ extraction. The maximum extraction efficiency was observed for the biosurfactant solution (Olimpicon GC, 15\%), for which the $\mathrm{Hg}$ extraction was shown to be 3.6-fold higher than for the 0.2 M EDTA, and this suggests its application in enhanced-EK treatment for the remediation of high $\mathrm{Hg}$-contaminated sediments.

(ii) The reduction of current intensity and electroosmotic flow with time observed during the preliminary EK test highlights the necessity of using conditioning agents during the treatment. Data demonstrates the good working features of the experimental apparatus.

(iii) Preliminary results show that EK treatment jointly with biosurfactants such as sugar esters could be a better choice for the remediation of $\mathrm{Hg}$-polluted sediments. The results obtained are of scientific and practical interest; however the optimal dosage of biosurfactants should be investigated by means of the bench-scale apparatus and further experiments aimed at investigating the effect of the mixture concentration on biodegradability, electroosmotic flow, and contaminant removal.

\section{Conflict of Interests}

The authors declare that there is no conflict of interests regarding the publication of this paper.

\section{References}

[1] A. Careghini, S. Dastoli, G. Ferrari et al., "Sequential solidification/stabilization and thermal process under vacuum for the treatment of mercury in sediments," Journal of Soils and Sediments, vol. 10, no. 8, pp. 1646-1656, 2010.

[2] R. di Leonardo, G. Adelfio, A. Bellanca, M. Chiodi, and S. Mazzola, "Analysis and assessment of trace element contamination in offshore sediments of the Augusta Bay (SE Sicily): a multivariate statistical approach based on canonical correlation analysis and mixture density estimation approach," Journal of Sea Research, vol. 85, pp. 428-442, 2014.

[3] ICRAM (Istituto Centrale per la Ricerca scientifica e tecnologica Applicata al Mare), "Valutazione preliminare dei dati della caratterizzazione ambientale della Rada di Augusta e aree prioritarie ai fini della messa in sicurezza di emergenza. Sito di bonifica di interesse nazionale di Priolo," Roma, 33 (BoIPr-SIGP-Rada di Augusta-01.02), 2005.

[4] M. Pazos, O. Iglesias, J. Gómez, E. Rosales, and M. A. Sanromán, "Remediation of contaminated marine sediment using electrokinetic-Fenton technology," Journal of Industrial and Engineering Chemistry, vol. 19, no. 3, pp. 932-937, 2013.

[5] G. de Gioannis, A. Muntoni, A. Polettini, and R. Pomi, "Enhanced electrokinetic treatment of different marine sediments contaminated by heavy metals," Journal of Environmental Science and Health, Part A: Toxic/Hazardous Substances and Environmental Engineering, vol. 43, no. 8, pp. 852-865, 2008.

[6] K.-J. Kim, D.-H. Kim, J.-C. Yoo, and K. Baek, "Electrokinetic extraction of heavy metals from dredged marine sediment," Separation and Purification Technology, vol. 79, no. 2, pp. 164169, 2011.

[7] F. Rozas and M. Castellote, "Electrokinetic remediation of dredged sediments polluted with heavy metals with different enhancing electrolytes," Electrochimica Acta, vol. 86, pp. 102109, 2012.

[8] A. Colacicco, G. de Gioannis, A. Muntoni, E. Pettinao, A. Polettini, and R. Pomi, "Enhanced electrokinetic treatment of marine sediments contaminated by heavy metals and PAHs," Chemosphere, vol. 81, no. 1, pp. 46-56, 2010.

[9] J. Wang, X. Feng, C. W. N. Anderson, Y. Xing, and L. Shang, "Remediation of mercury contaminated sites-a review," Journal of Hazardous Materials, vol. 221-222, pp. 1-18, 2012.

[10] J. D. Subirés-Muñoz, A. García-Rubio, C. Vereda-Alonso et al., "Feasibility study of the use of different extractant agents in the remediation of a mercury contaminated soil from Almaden," Separation and Purification Technology, vol. 79, no. 2, pp. 151156, 2011.

[11] H. K. Hansen, L. M. Ottosen, L. Hansen, B. K. Kliem, A. Villumsen, and G. Bech-Nielsen, "Electrodialytic remediation of soil polluted with heavy metals: key parameters for optimization of the process," Chemical Engineering Research and Design, vol. 77, no. 3, pp. 218-222, 1999. 
[12] J. Thöming, B. K. Kliem, and L. M. Ottosen, "Electrochemically enhanced oxidation reactions in sandy soil polluted with mercury," Science of the Total Environment, vol. 261, no. 1-3, pp. 137-147, 2000.

[13] K. R. Reddy and R. E. Saichek, "Effect of soil type on electrokinetic removal of phenanthrene using surfactants and cosolvents," Journal of Environmental Engineering, vol. 129, no. 4, pp. 336-346, 2003.

[14] L. Cox, M. C. Hermosin, and J. Cornejo, "Sorption of metamitron on soils with low organic matter content," Chemosphere, vol. 32, no. 7, pp. 1391-1400, 1996.

[15] M. D. Garcia-Gutierrez, C. Gomez-Lahoz, J. M. RodriguezMaroto, C. Vereda-Alonso, and F. Garcia-Herruzo, "Electrokinetic remediation of a soil contaminated by the pyritic sludge spill of Aznalcollar (SW, Spain)," Electrochimica Acta, vol. 52, no. 10, pp. 3372-3379, 2007.

[16] A. García-Rubio, J. M. Rodríguez-Maroto, C. Gómez-Lahoz, F. García-Herruzo, and C. Vereda-Alonso, "Electrokinetic remediation: the use of mercury speciation for feasibility studies applied to a contaminated soil from Almadén," Electrochimica Acta, vol. 56, no. 25, pp. 9303-9310, 2011.

[17] N. S. Neta, C. S. J. dos Santos, S. O. Sancho et al., "Enzymatic synthesis of sugar esters and their potential as surface-active stabilizers of coconut milk emulsions," Food Hydrocolloids, vol. 27, no. 2, pp. 324-331, 2012.

[18] A. Szulc, D. Ambrozewicz, M. Sydow et al., "The influence of bioaugmentation and biosurfactant addition on bioremediation efficiency of diesel-oil contaminated soil: feasibility during field studies," Journal of Environmental Management, vol. 132, pp. 121-128, 2014.

[19] R. Chandankere, J. Yao, M. Cai, K. Masakorala, A. K. Jain, and M. M. F. Choi, "Properties and characterization of biosurfactant in crude oil biodegradation by bacterium Bacillus methylotrophicus USTBa," Fuel, vol. 122, pp. 140-148, 2014.

[20] C. N. Mulligan and F. Eftekhari, "Remediation with surfactant foam of PCP-contaminated soil," Engineering Geology, vol. 70, no. 3-4, pp. 269-279, 2003.

[21] S. Wang and C. N. Mulligan, "An evaluation of surfactant foam technology in remediation of contaminated soil," Chemosphere, vol. 57, no. 9, pp. 1079-1089, 2004.

[22] W. Wang, F. Wu, J. Zheng, and M. H. Wong, "Risk assessments of PAHs and $\mathrm{Hg}$ exposure via settled house dust and street dust, linking with their correlations in human hair," Journal of Hazardous Materials, vol. 263, pp. 627-637, 2013.

[23] S. Wieczorek, H. Weigand, M. Schmid, and C. Marb, "Electrokinetic remediation of an electroplating site: design and scale-up for an in-situ application in the unsaturated zone," Engineering Geology, vol. 77, no. 3-4, pp. 203-215, 2005.

[24] S. C. Crawford, C. J. Bruell, D. K. Ryan, and J. W. Duggan, "Effects of emulsion viscosity during surfactant-enhanced soil flushing in porous media," Journal of Soil Contamination, vol. 6, no. 4, pp. 355-370, 1997. 

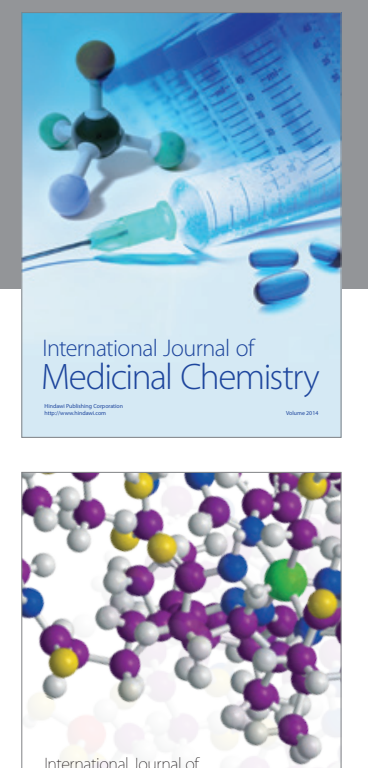

\section{Carbohydrate} Chemistry

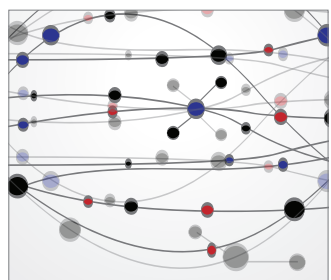

The Scientific World Journal
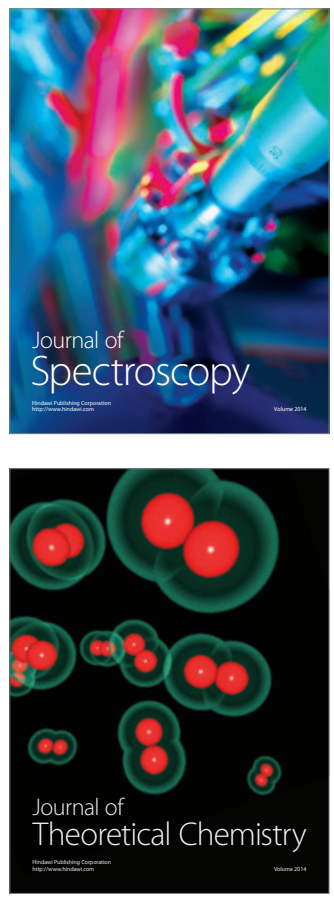
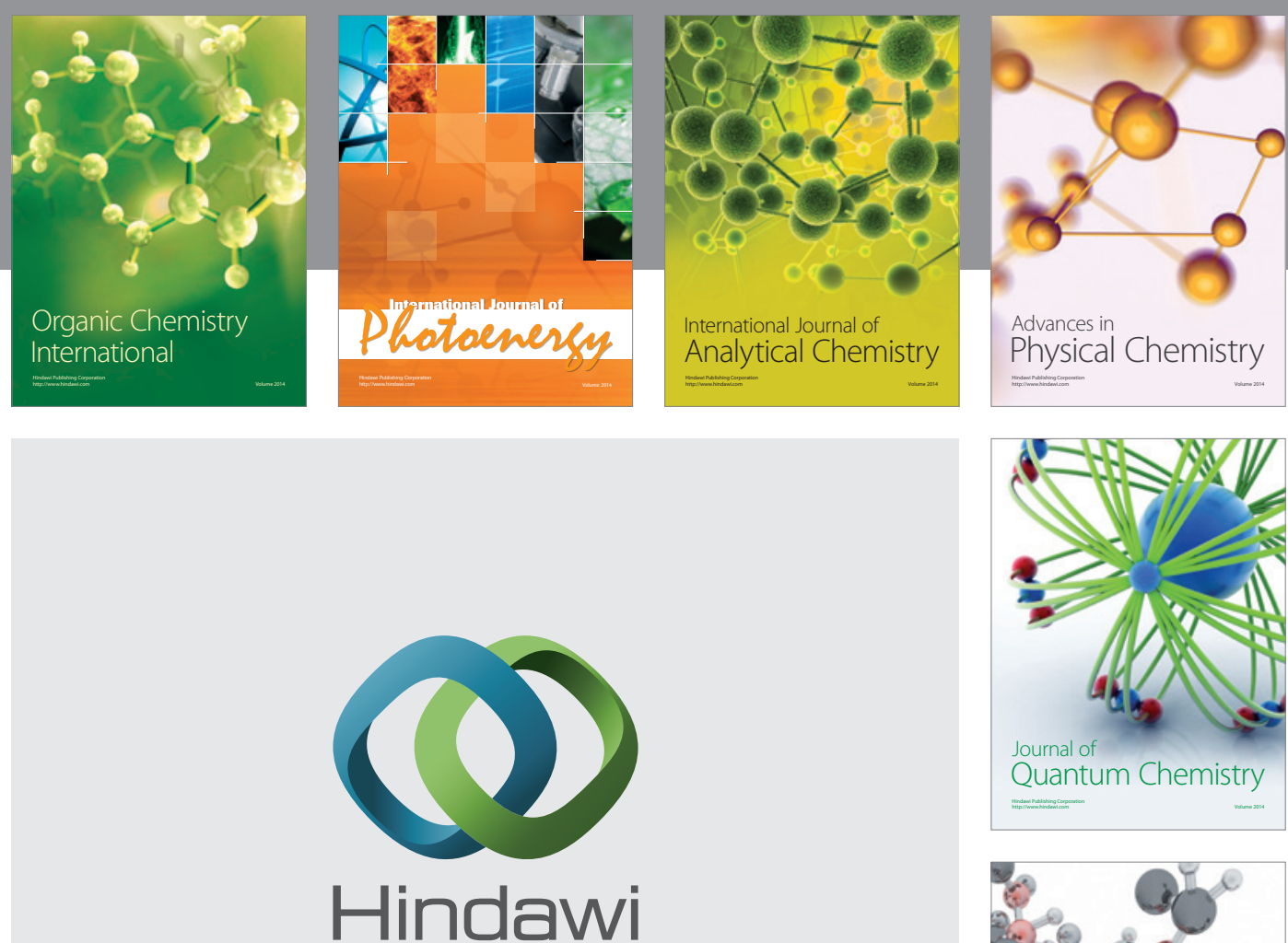

Submit your manuscripts at

http://www.hindawi.com

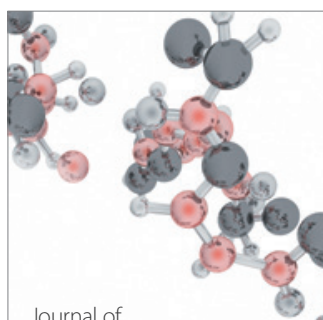

Analytical Methods

in Chemistry

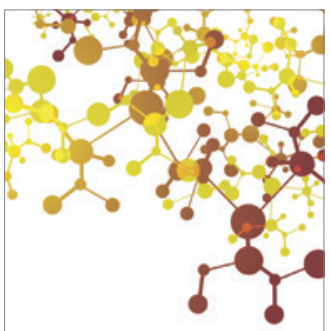

Journal of

Applied Chemistry

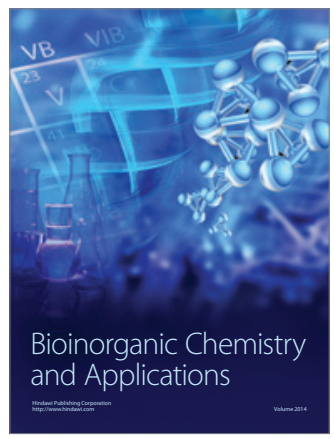

Inorganic Chemistry
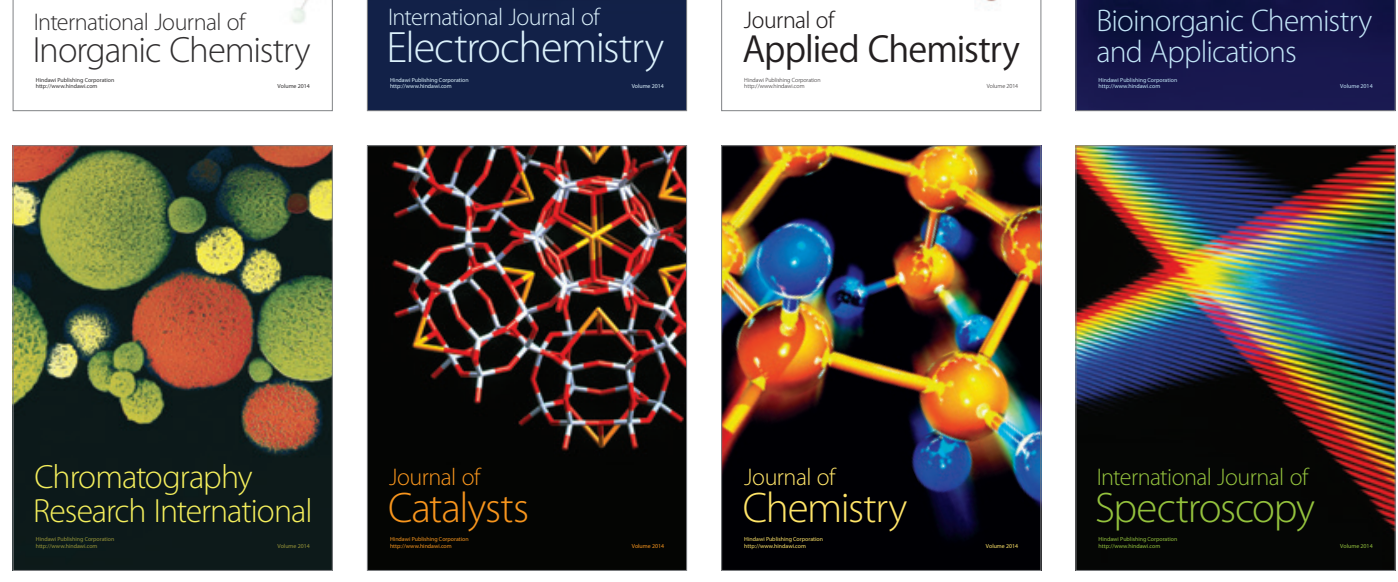